\title{
What Matters Most? Determinants of Administrative Effectiveness
}

\author{
Khuda Bakhsh", Azhar Mumtaz Saadi, Shafqat Rassol \\ Assistant Professor, GC University, Faisalabad \\ *Corresponding author: gallantup@yahoo.com
}

Received October 20, 2014; Revised November 07, 2014; Accepted November 19, 2014

\begin{abstract}
The study focused on certain factors influencing the effectiveness of Heads of Departments in public sector universities. The researcher developed a questionnaire to measure the determinants and the effectiveness was measured by Leadership Practices Inventory LPI. A sample of five hundreds teachers from twenty one randomly selected universities participated in the study. Regression analysis of the collected data was made to answer 'How well the selected factors influence the administrative effectiveness of Heads of Departments (HoDs)'. It was found that all the selected factors are positively correlated with administrative effectiveness. Personality Traits proved as strongest determinant followed by organizational climate with significant predictive powers.
\end{abstract}

Keywords: administrative effectivess, organizational climate, personality traits

Cite This Article: Khuda Bakhsh, Azhar Mumtaz Saadi, and Shafqat Rassol, "What Matters Most? Determinants of Administrative Effectiveness." American Journal of Educational Research, vol. 2, no. 11 (2014): 1088-1090. doi: 10.12691/education-2-11-13.

\section{Introduction}

Administration is name of 'get the work done' well in time saturated with quantity and quality. It is an easy \& enjoyable if the administrator is enriched with desired personal traits and management skills Otherwise it is full of tension at the same time (Tanveer \& Khan, 2014). The administrator makes a visible plan to achieve the predetermined objectives of the organization but fails if the organizational climate is not supporting him (Avolio, 2011; Azhar, 2009; Mandel, 2012; Rubab, 2012 ).

The interpersonal behavior with his subordinates, society and superordinate is the reflection of his personality and academic potential. There may be obstacles in administration but an effective head is likely to take over and find an acceptable way out to ease the situation accordingly.

Leading is to display the following five activities

- Modeling the way

- Inspiring a shared vision

- Challenging the process

- Enabling others to act

- Encouraging the heart

What are the factors to make up the effectiveness of heads/principals? Throughout the years, a variety of constructs and predictors have been posited as determinants of administrative effectiveness including age, sex, values and even genetic factors. An effective head/principal intends to demonstrate a clear picture of his personality traits to lead his staff so they work with due interest and pleasure (Stronge, 2012).

\section{Review of Related Literature}

Every society happens to establish and develop many organizations in course of time to achieve the predetermined goals. They serve a variety of socio-economic. Politico-religious and other purposes. Depending upon their variety of purposes, they differ in their structure and functioning, in scope and size, in their control and management and also in their efficiency and outcomes (Azhar, 2013; Tanveer, 2010; Ansar, 2014). Schools, colleges and universities are unique organizations designed to achieve specific goals of preparing good citizens. It is the education that plays a vital role in realizing the hopes and aspirations of the society but only when it becomes an effective instrument for delivering the intended goals.

The pace and momentum of change largely depends upon the efficiency and effectiveness with which the institution is being managed. It is needless to say that colleges/universities which are better managed produce better educational products (Ijaz, 2014). Since the success of an educational organization depends upon the effective administration, study of administrative effectiveness has received much attention of scholars in the field of educational research. What determines the effective educational administration is a question of vital significance to effective teaching-learning process. A proper understanding of effective administrator envisages that these factors and forces be understood and their specific contribution be determined. Such an attempt would make it possible to experiment with administration so they work better than what they were working earlier. 
The trait theory holds that administration is best conceived as art. Thus the successful administrator is one who has a large number of traits required for the practice of this art.

The personal quality theory or Trait centered approach to leadership studies which came first based on the opinion widely held by outstanding educationists, social scientists and philosophers that:

- Leaders are born not made

- The world is divided into "Leaders" and "Followers" right from birth

In this theory, leaders were believed to possess certain qualities as well as quantitative traits which followers lacked. Such attributes or traits were high intelligence, charisma, body shape or body building, family status (Rabab, 2012).

Trait theory states that there are certain traits which are occupied by the leaders. Person having these traits will be a good leader. Majority of social studies focus on these traits as determinants of an effective leadership.

The theory is also called "great man" theory of leadership, emphasized that certain peoples are called leaders because they possess inborn qualities of their characters such as good personality, values, motives, traits and skills, which yield "natural leaders" (Sandeep, 2009; DeNeve, 2006). The "great man” dimension of leadership also points out that these characteristics allow the persons which are called leaders in the hierarchy to ascend above all, these characteristics are permanent and cannot be changed by the environmental factors.

The list of personality traits demonstrated by effective leaders tends to be very long. There are more than 500 studies which are searching for the unique qualities and inherent traits of effective leaders. However, using sophisticated techniques, the researchers confirmed that effective leaders do possess certain traits as following:

Traits - alert to social environment, dependable, dominant, physically beautiful, ambitious and achievement oriented, gallant, exciting, assertive, cooperative, adaptable to situations, decisive, willing to assume responsibility, energetic, having good sense of humor, persistent, self-confident, tolerant of stress.

One of the flaws of this trait theory is that it did not involve situational and environmental correlates of leadership success (Rubab, 2012). School climate is a significant predictor of administrative effectiveness. If the organizational is supportive enriched with safety, good environment and desirable interpersonal relationship then the administration is enjoyable.
Research is done on burning issues, based on the findings of such studies, it is imperative to investigate the phenomenon with due interest and pleasure to penetrate into problem positively.

\subsection{Statement of the Problem}

The researcher intends to find certain factors which make the heads of teaching departments more effective.

\subsection{Research Questions}

The main research question was 'how well the selected factors taken as determinant contribute to administrative effectiveness'? The following research question excited the mind of the researcher to be answered.

- What is the individual contribution of each determinant to the variance of administrative effectiveness?

- What is combined contribution of organizational climate and personal traits to the variance of administrative effectiveness?

\subsection{Population and Sample of the Study}

The population of the study consists of all the teachers working in public sector universities of the Punjab. A sample of five hundreds teachers from twenty one randomly selected universities participated in the study, who marked the administrative effectiveness of their respective heads of departments.

\subsection{Research Instrument}

The researcher developed a questionnaire to measure the determinants and the heads' effectiveness was measured by Leadership Practices Inventory LPI.

\subsection{Data Analysis}

The collected data was entered into SPSS for regression analysis to answer the research questions.

\section{Results}

\subsection{Linear Regression Analysis of the TWO determinants with the Administrative effectiveness}

Table 1. Individual contribution of 'Organizational Climate' to Administrative Effectiveness

\begin{tabular}{|c|c|c|c|c|}
\hline Model & $\mathrm{R}$ & $\mathrm{R}$ Square & Adjusted R Square & Std. Error of the Estimate \\
\hline 1 & $.332^{\mathrm{a}}$ & .110 & .108 & 6.051 \\
\hline \multicolumn{4}{|c|}{ a. Predictor: (Constant), Organizational Climate } \\
\hline
\end{tabular}

Table 1 shows that school climate is a significant $\left(\mathrm{R}^{2}=.110, \mathrm{p}<.05\right)$ determinant of heads' /principals' administrative effectiveness. This means that $11 \%$ of the variance in principal's leadership effectiveness is

influenced by the department climate. A Supportive learning environment suitable for teaching-learning process makes the administrator more effective.

Table 2. Individual contribution of 'Personal Traits' to Administrative Effectiveness

\begin{tabular}{|c|c|c|c|c|}
\hline \multicolumn{7}{|c|}{ Table 2. Individual contribution of 'Personal Traits' to Administrative Effectiveness } \\
\hline Model & $\mathrm{R}$ & $\mathrm{R}$ Square & Adjusted R Square & Std. Error of the Estimate \\
\hline 2 & $.612^{\mathrm{a}}$ & .375 & .373 & 5.172 \\
\hline \multicolumn{5}{|c|}{ a. Predictor : (Constant), Personality traits } \\
\hline
\end{tabular}

Table 2 shows that personality traits is the strongest $\left(\mathrm{R}^{2}=.375, \quad \mathrm{p}<.05\right) \quad$ determinant of administrative effectiveness. It exhibits that 37\% variance in leadership effectiveness is determined by his personality traits. 


\subsection{Multiple Regression Analysis of with the Administrative Effectiveness Organizational Climate \& Personality Traits}

Table 3. Joint contribution (cumulative effect of the all variables on the dependent variable) of Organizational Climate and Personality Traits to the variance of the leadership effectiveness

\begin{tabular}{|c|c|c|c|c|}
\hline \multicolumn{5}{|c|}{ Model Summary } \\
\hline Model & R & R Square & Adjusted R Square & Std. Error of the Estimate \\
\hline 1 & $.612 \mathrm{a}$ & .375 & .373 & 5.072 \\
\hline 2 & $.673 \mathrm{~b}$ & .454 & .451 & 4.748 \\
\hline \multicolumn{5}{|c|}{ a. Predictors: (Constant), Personality traits } \\
\hline
\end{tabular}

Table 3 (stepwise multiple regressions)depicts that Personality Traits of the administrator alone accounted for $37 \%$ of the variance in his administrative effectiveness. When the department Climate was included, the variance was raised by $12 \%$ as $\mathrm{R}^{2}$ rose to. 454 . The combined influence of the TWO determinants is $45 \%$, it means that there may be unknown factors to be explored in next research.

\section{Conclusions}

The organizational climate must be supportive and attractive to accelerate the teaching-learning process. The teachers should cooperate with the head/principal. There should not be any tension/conflict among the teachers. They should be practically loyal to the institution. Next the head should be enriched with the best personal traits in this regard.

\section{Discussions}

As it has been well proven by the perceptions of university teachers that organizational climate and the Personality traits of the administrator are the best determinants of his administrative effectiveness, the same results may be generalized to all organizations run by government of Pakistan. School/organizational environment vary greatly. Whereas some schools have friendly, inviting, supportive, happy learning environment, others feel exclusionary, unwelcoming and even unsafe In a happy learning environment, people are inspired to their best. In such an environment, the leadership is very effective in his key function of 'enabling others to act'. As they are happy and excited with the provided climate, accomplish their duties with great vim, vigor and pleasure. so it is very easy to get the work done well in time. The head of department can perform better in a climate conducive to teaching-learning process. Next the administrator who is honest, cooperative, straight forward, dependable with attractive looks and good sense of humor is more effective.

\section{Recommendations for Further Research}

Having completed the study, the researcher realized that there is great scope for new studies in the area of leadership effectiveness. To begin with the researcher wishes to point out that there is an interesting scope on defining and explaining the concept of 'leadership effectiveness' as this concept has not been defined uniformly and specifically till now. Research is further needed in this direction.

This study opens the doors wider for the study of variables related to principal effectiveness at workplace.

The principal effectiveness is influenced by several factors. The predictor variables selected for this study jointly contributed $45 \%$ to the variance on the Heads' administrative effectiveness. It gives a clear indication to search for new variables. Quite a number of other factors/ variables can be hypothesized as determinants of principal effectiveness. The association of other factors with effective educational management requires further study in this direction. Replication of this study in other provinces of Pakistan, viz; Sindh, Baluchistan and Khyber Pakhtun Khaw would be worthwhile to conduct.

\section{References}

[1] Ansar,A. (2014). Personal Traits of Khan Tribes. Ghadeer Publishers. Kohat.

[2] Avolio, B., \& Bass, B. (2009).Multifactor Leadership Questionnaire (MLQ). Mind Garden.

[3] Azhar, A. (2013). Factors influencing the administrative behavior. Journal of Educational Administration, 55 (2). 110-121.

[4] DeNeve, K. (2009). The Happy Personality: A meta-analysis of 110 personality traits and subjective wellbeing. Psychological Bulletin, 11 (112-118).

[5] Hughes, L.W. (2011). The Principal as Leader. Second Edition. NJ: Prentice-Hall.

[6] Ijaz, H. (2014). Biological Dimensions of beauty. HAIDER Publishers. Karachi (Pakistan).

[7] Mandel, S. (2012). What new teachers really need? The Journal of Educational Leadership, 65 (5), 9-14.

[8] Rubab, Z. (2012). School Climate and job satisfaction among secondary school teachers in Punjab.M.Phil dissertation, Preston University.

[9] Sandeep, C. (2009). Educational Management. Pearson Publishers. New Delhi.

[10] Stronge, J.H., Canto, B. (2012). Qualities of effective principals.Alexanderia, VA: Association for Supervision and Curriculum Development (ASCD).

[11] Tanveer, A. (2014). The Challenges in university administration. Journal of Education Policy, Planning and Administration JEPPA, 9 (5), 95-110.

[12] Tanveer, A. (2010). Determinants of job performance in public sector universities of Pakistan. Gomal University Journal of Educational Research, 5 (110-114). 